\title{
Changing Wisdom of Metallic Alloys Development
}

\author{
Manoj Gupta \\ Department of Mechanical Engineering, NUS, Singapore, Singapore \\ Email:mpegm@nus.edu.sg
}

How to cite this paper: Gupta, M. (2018) Changing Wisdom of Metallic Alloys Development. Materials Sciences and Applications, 9, 1021-1035.

https://doi.org/10.4236/msa.2018.913074

Received: September 19, 2018

Accepted: December 14, 2018

Published: December 17, 2018

Copyright (C) 2018 by author and Scientific Research Publishing Inc. This work is licensed under the Creative Commons Attribution International License (CC BY 4.0).

http://creativecommons.org/licenses/by/4.0/

\begin{abstract}
Metallic alloys have been instrumental through the ages in shaping the progress of human civilization. The development of the alloys from ancient to present time initiated from accidents to through the use of well-defined scientific principles. This article provides a snapshot of the alloys development from ancient to present time and the likely future direction.
\end{abstract}

\section{Keywords}

Metal, Alloy, Composites, High Entropy Alloys

\section{Introduction}

Materials have played a key role in evolution of humans from prehistoric times. The development, discovery and use of materials are largely responsible for easing their work pressure while continuously contributing to an enhancement in their comfort levels and social development [1]. For example, use of stones as tools assisted humans in self-defense and hunting thus securing their lives better while simultaneously providing them with much needed food and clothes in ancient times.

The development of materials progressed more scientifically over last two centuries and currently materials can be classified into four categories [1]. Their salient features are given below:

1) Polymers: Polymers are lightweight and corrosion resistant materials used in diverse spectrum of applications where strength and stiffness are not the primary design criteria. Polymers can be transparent and often serve to replace ceramic glasses. Applications of polymers include home appliances, casings of electronic gadgets, stationary items, coatings etc.

2) Ceramics: Ceramics are typically hard and brittle materials with low frac- 
ture toughness. They are made of a metallic and non-metallic atoms bonded through ionic, covalent or mix of them. They are good insulators and thermally stable at higher temperatures. They are most commonly used in infrastructural applications, as insulators, fibers and abrasives.

3) Metals: Metals are class of materials that are capable of conducting electricity at a temperature of absolute zero. Generally, they exhibit good combination of strength and ductility and can conduct heat. They can be used at temperatures intermediate between the application domains of polymers and ceramics. They are widely used in practically all applications ranging from aerospace industry to home appliances.

4) Composites: Composites materials are blend of different categories of materials and are capable of exhibiting the properties that cannot be displayed by their constituting counterparts. Typically ceramics are used as reinforcements in metals or plastics to enhance their targeted properties governed by the end application.

As evident, each category of materials has its own unique significance and their application zone that is principally governed by their unique microstructure governed properties. In modern applications, these materials co-exist. As an example in automobiles, we can see different parts made of polymers (interiors), metals (body and engine), composites (fiber reinforced plastics) and ceramics (glasses). The relative dominance of any type of above stated category of materials depends on the spectrum and combination of properties that they can exhibit. For example, ceramics exhibit excellent properties under compression and high temperature and hence they are accordingly used in infrastructural applications and as insulation materials in high temperature environment such as in furnaces. On the other hand, polymers are not able to withstand high temperature and exhibit low modulus and accordingly used where these two service conditions are absent. Polymers are usually light and deformable and hence are used for example in weight-critical applications. As a result of vast difference in properties of metals, polymers and ceramics, composites were developed to bridge the gap between any two categories of materials while exhibiting a combination of properties that can be tailored based on end applications. Composites are therefore used in infrastructural applications from ancient times to modern times in addition to more targeted applications in space, aerospace and automobile sectors. To note that composites are also favored by nature as our bone and wood are classical examples of nature built composites [2] [3]. Metals and alloys form a unique category of materials as they can circumvent disadvantages of ceramics (such as low toughness) and polymers (such as low elastic modulus and high temperature capabilities) and provide various combination of properties enabling their use in a wide spectrum of applications. Over the ages, metal based materials have been developed through:

1) Compositional control: Alloys irrespective of the primary base metal with diverse combinations of properties are often realized primarily through composition control with classical examples such as stainless steel, had field steel and 
maraging steels in case of iron based alloys. A method currently and continuously pursued actively.

2) Heat treatment: Heat treatments are often utilized to realize different combination of properties even maintaining the same composition and to enhance certain characteristics of the metallic alloys. Evolution of T4, T6, hardening and tempering are some such examples.

3) Processing control: The interrelation between processing microstructure and mechanical properties is well known. Accordingly, the nature of primary processing (such as casting or powder metallurgy) and secondary processing (such as rolling, forging or extrusion) can result in alloys of the same composition displaying totally different combination of properties.

While the compositional variation was primarily utilized till nineteenth century, the development of characterization tools picked up in early twentieth century with the development of transmission electron microscope and $\mathrm{x}$-ray diffractometer. With the increasing understanding of the structure of metals, phase diagrams started to appear in later part of nineteenth century and in early twentieth century initiating the golden era of alloy development through compositional and heat treatment control (accidental discovery of age hardenable $\mathrm{Al}$ alloy Duralumin) [4].

\section{Traditional Alloys}

Metallic alloys were made and used by humans from prehistoric time mostly through experimental trials and without any scientific knowledge. Notable examples are BUTP steel in ancient India, Damascus and Moorish steel in middle ages and Sheffield steel in $14^{\text {th }}$ century. The iron pillar (6000 kg) in New Delhi, India erected in $402 \mathrm{CE}$ is still considered a metallurgical wonder as it has not corroded so far (Figure 1) [5]. To note that till $18^{\text {th }}$ century, it was not known

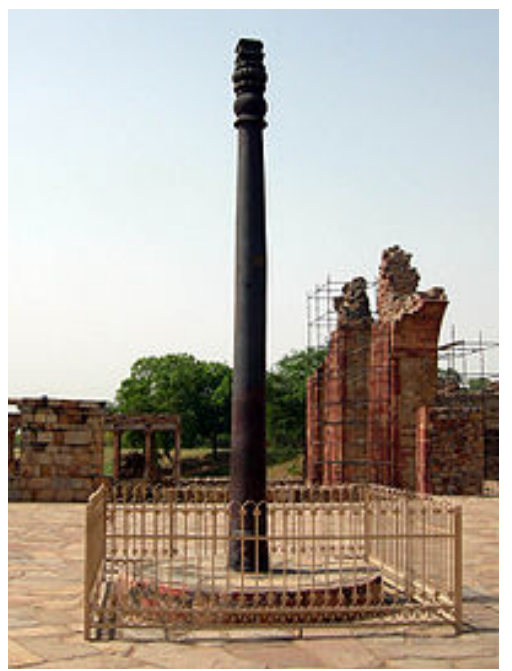

Figure 1. The iron pillar of Delhi, India [Chemical composition: $0.15 \%$ carbon, $0.25 \%$ phosphorus, $0.005 \%$ sulfur, $0.05 \%$ silicon, $0.02 \%$ nitrogen, $0.05 \%$ manganese, $0.03 \%$ copper, $0.05 \%$ nickel, and balance iron] [7]. 
that steel is an alloy of iron and carbon and further the concept of heat treatment remained unexplained till end of $19^{\text {th }}$ century [4] [6]. With the increased understanding of phase diagrams and emergence of microstructural characterization tools, new alloys started to emerge. Most of the alloys were and still based on eutectic (such as $\mathrm{Al}-\mathrm{Si}$ and $\mathrm{Al}-\mathrm{Cu}$ systems) and eutectoid (plain carbon steels) systems and some on peritectic systems (Al-Ti system). Table 1 shows some of the commonly used metallic alloys that are widely used in multiple engineering applications.

Improvement and variation in properties were realized principally through judicious composition (Figure $2 \&$ Figure 3 ), heat treatment control (Figure 4) and processing (Figure 5). For example, fundamental understanding of heat treatment allowed the researchers to develop steels with various microstructural features through variation in heat treatments (TTT: Time-temperature-transformation diagrams). Similarly, in the case of non-ferrous materials such as aluminum, precipitation strengthening (such as T4 and T6 conditions) was utilized to realize different properties even by keeping the same composition [8]. The variation in composition in $\mathrm{Al}$ alloys, for example, led to 8 series (1 $\mathrm{xxx}$ to $8 \mathrm{xxx}$ ) of wrought alloys and similarly different types of steels (plain carbon steels, alloy steels, tool steels, specialty steels etc.). Traditional alloys such as mentioned above are still being used widely in many engineering applications [1] [2] [7]. The effect of secondary processing to realize good strength is perhaps best demonstrated by Samurai swords where thermomechanical processing was very intelligently used (Figure 5) [9].

As a result of rapid pace of technological advance in past few decades and emergence and rapid growth in engineering sectors such as automobile and aerospace posed the need to develop higher performance metallic materials due to ever increasing stringent service conditions. Development of nickel based superalloys, damage tolerant titanium alloys and maraging steels are some such

Table 1. List of Some of the Most Commonly Used Metals in Applications.

\begin{tabular}{cl}
\hline Metal/Metallic Alloys & \multicolumn{1}{c}{ Applications } \\
\hline Fe/Fe based alloys-Steels & Transportation sector and infrastructural application, biomedical sector. \\
Al/Al based alloys & $\begin{array}{l}\text { Weight critical applications in transportation sector, sports sector and } \\
\text { electronic sector. }\end{array}$ \\
Cu/Cu based alloys & $\begin{array}{l}\text { The best material for electricity transmission, infrastructural } \\
\text { applications, electronic sector, defense applications, marine industry. }\end{array}$ \\
Zn/Zn based alloys & $\begin{array}{l}\text { Automobile, construction, shipbuilding, household electrical appliances } \\
\text { and galvanizing. }\end{array}$ \\
Ni based alloys & $\begin{array}{l}\text { High temperature applications such as in engines and heating elements. } \\
\text { They can also be used where shape memory effect is required. }\end{array}$ \\
Ti based alloys & $\begin{array}{l}\text { Light weight structures, defense applications, aerospace sector, and } \\
\text { biomedical sector. }\end{array}$ \\
Mg based alloys & $\begin{array}{l}\text { Weight critical applications in transportation sector, sports sector and } \\
\text { electronic sector. }\end{array}$ \\
& Most commonly used as lead free solders in electronic industry.
\end{tabular}



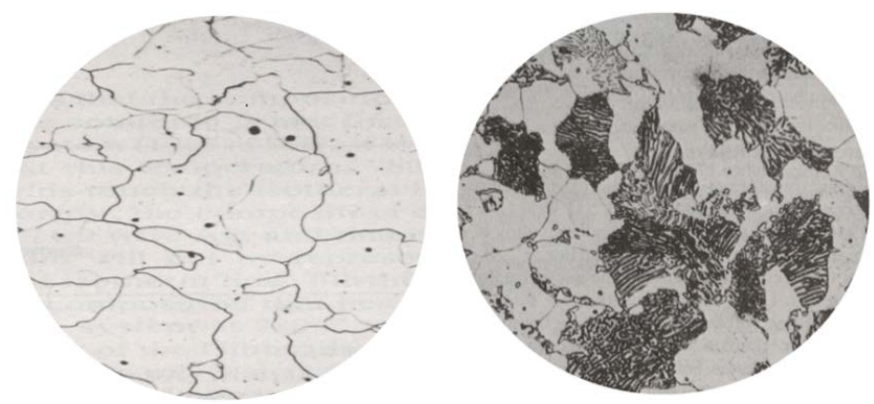

Figure 2. Effect of compositional control on the microstructure of steels which assisted in increasing strength (from $\sim 300 \mathrm{MPa}$ to $\sim 500 \mathrm{MPa}$ ) when the carbon content changed from $0.2 \%$ to $0.4 \%$.
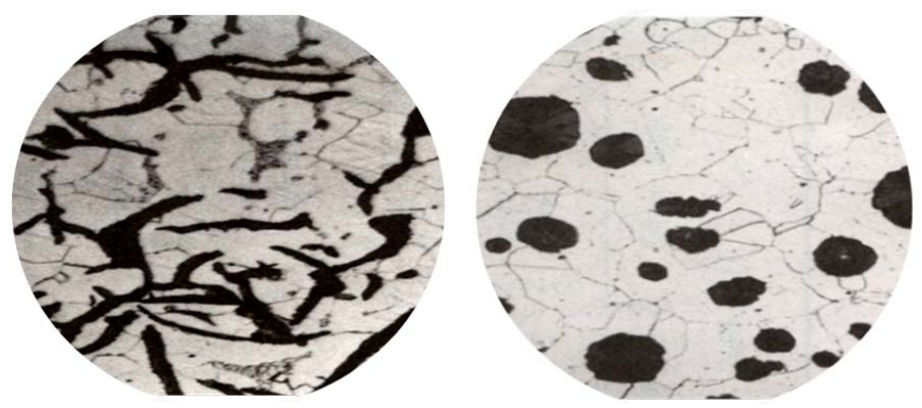

Figure 3. Effect of compositional control (addition of $\mathrm{Mg} / \mathrm{Ce}$ ) on the microstructure of grey cast iron (left) which made it stronger and tougher through change in morphology (from flake type to globular) of graphite flakes (right).
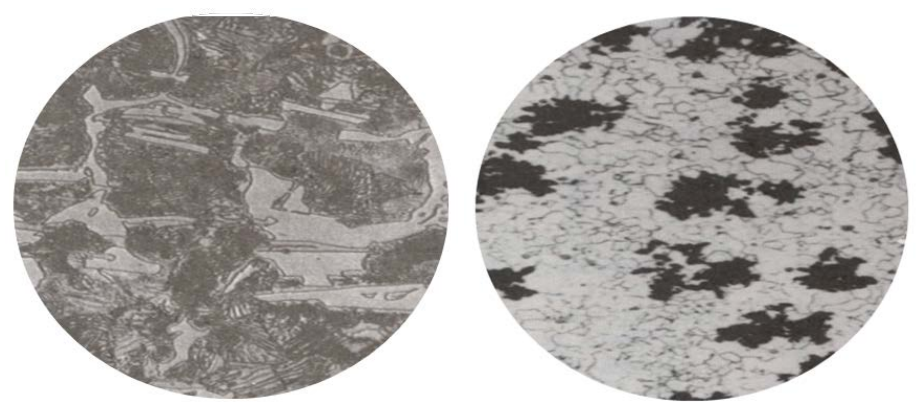

Figure 4. Classical effect of heat treatment of white cast iron (left) in affecting microstructural variation leading to the formation of tougher malleable cast iron (right). The hard phases were broken down into their elementary components.

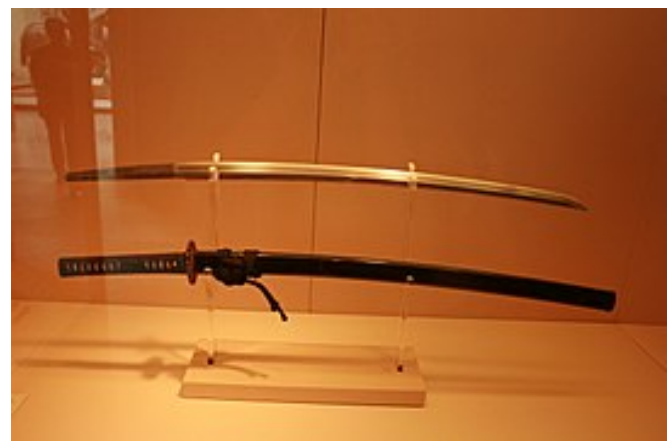

Figure 5. Samurai sword realize their properties through intelligent processing [9]. 
examples of alloys developed in recent decades and used extensively. Last two decades have also seen the emergence of new magnesium based alloys due to their light weight and capability to reduce greenhouse gas emissions [10] [11]. Automobile companies like Mercedes-Benz, Porsche, Volkswagen group, Mitsubishi Motors and BMW have already used light magnesium based alloys in many parts of cars to realize fuel savings [10] [11] (Figure 6). Some of the metallic alloys that were and are used in widespread applications are listed in Table 2 and are arranged in the descending order of their densities.

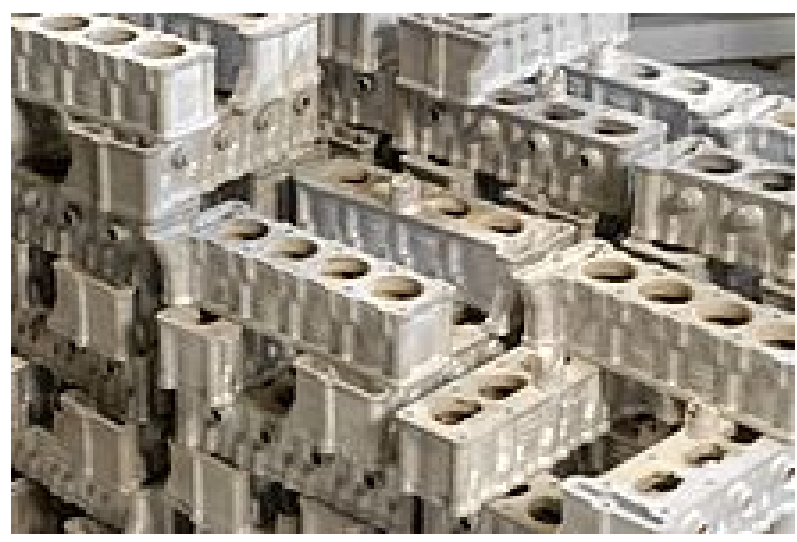

Figure 6. $\mathrm{Mg}$ alloy motorcycle engine blocks to minimize fuel consumption through weight saving [11].

Table 2. Mechanical properties of selected metallic alloys that are/were widely used in engineering applications.

\begin{tabular}{|c|c|c|c|c|c|}
\hline Type of Alloy & $\begin{array}{l}\text { Yield Strength } \\
\text { (MPA) }\end{array}$ & UTS (MPa) & Failure Strain (\%) & $\begin{array}{c}\text { Density } \\
(\mathrm{g} / \mathrm{cc})\end{array}$ & Reference \\
\hline $\begin{array}{l}\text { UNS N10276: Ni } \\
\text { superalloy (C276) }\end{array}$ & $\begin{array}{c}204 \\
2.4 \mathrm{~mm} \text { thickness, } \\
429^{\circ} \mathrm{C}\end{array}$ & $\begin{array}{c}601 \\
4.8-25.4 \mathrm{~mm} \\
\text { thickness, } 538^{\circ} \mathrm{C}\end{array}$ & $\begin{array}{c}56 \\
1.6-4.7 \mathrm{~mm} \\
\text { thickness, } 204^{\circ} \mathrm{C}\end{array}$ & 8.89 & [12] \\
\hline $\begin{array}{c}\text { Cartridge Brass } \\
(70 / 30)\end{array}$ & $\begin{array}{c}76-448 \\
\text { (Depends on } \\
\text { temper) }\end{array}$ & $\begin{array}{c}303-896 \\
\text { (Depends on } \\
\text { temper) }\end{array}$ & 66 & 8.53 & [13] \\
\hline SS304 steel & 215 & 505 & 70 & 8 & [14] \\
\hline $\begin{array}{c}\text { Maraging steel } \\
\text { ASTM A } 538\end{array}$ & 2617 & 2693 & 6 & 8 & {$[15]$} \\
\hline Mild steel: S275 & $245-275$ & $410-660$ & $20-22$ & 7.85 & {$[16]$} \\
\hline $\begin{array}{c}\text { Ti-6Al-4V: } \mathrm{Ti} \\
\text { alloy }\end{array}$ & $880-920$ & $900-950$ & $5-18$ & 4.5 & [17] \\
\hline $\begin{array}{c}\text { AA 7075: Al alloy } \\
\text { (T6) }\end{array}$ & $430-480$ & $510-540$ & $5-11$ & 2.81 & {$[18]$} \\
\hline AA 2024: Al alloy & Min. 345 & Min. 427 & 5 & 2.78 & [19] \\
\hline $\begin{array}{l}\text { AZ91: Mg alloy } \\
\text { (Die cast alloy) }\end{array}$ & 160 & 230 & 3 & 1.81 & [20] [21] \\
\hline AZ31: Mg alloy & 200 & 260 & 15 & 1.77 & {$[22]$} \\
\hline
\end{tabular}


While the research community is still engaged in developing new alloys based on the current fundamental understanding of the interaction between different elements, heat treatments, processing routes and the technological needs (such as light weighting for controlling environmental pollution), innovative efforts were also made in parallel to develop non-crystalline or amorphous metal based alloys.

\section{Amorphous Alloys/Metallic Glasses}

First reported in 1960 by Klement, Willens and Duwez [23], amorphous metals/alloys are the one that exhibit random atomic arrangement (absence of atomic periodicity) leading to absence of well-defined peaks in $\mathrm{x}$-ray diffractograms. Amorphous alloys generated lots of excitement and experimental curiosity and were initially formed as ribbons or small particles at high cooling rates $\left(10^{5}-10^{6} \mathrm{~K} / \mathrm{s}\right)$ [23] [24] [25]. The initial impact on applications of metallic glasses was limited due to the reasons related to:

1) Their dimension: One of the dimensions in earlier research pursuits was limited to typically less than 100 microns to ensure high heat transfer. They were produces in forms like powders, films, ribbons and foils with almost no engineering applications.

2) Cost: The cost of the metallic glasses was high due to batch process, limited amount of metals that can be transformed to glassy state besides the cost of primary constituents. For example the first metallic glass reported was Au-Si based [23].

3) Synthesis method: The methods (splat quenching, twin roller quenching, melt spinning etc.) that were able to create metallic glasses had to ensure a fast cooling rate $\left(10^{5}-10^{6} \mathrm{~K} / \mathrm{s}\right)$ were much beyond the capabilities of conventional processing types such as casting making them almost of no use for common engineering applications.

4) Compositional limitations: In the initial almost two decades, there were limited progress in expanding the number of compositions that can lead to formation of metallic glasses and at times it was perceived only as a scientific curiosity.

In 1990, Inoue and coworkers synthesized multicomponent glassy alloys using transition metals and at low cooling rates (as low as $\sim 10^{-3} \mathrm{~K} / \mathrm{s}$ ). Commonly known a bulk metallic glasses (BMGs), these alloys due to their millimeter size (> 1-mm) enabled the researchers to investigate their mechanical, physical and chemical properties (Figure 7) [26]. These results were seen as a quantum leap as the methods at low cooling rate can be scaled up and the dimensions in millimeter length scale can enable these materials to be used in much wider spectrum of engineering applications.

Attempts were made to stipulate the rules that lead to metallic glass formation and following crucial factors were identified:

1) Atomic packing density: Glass forming ability seems to increase with higher 


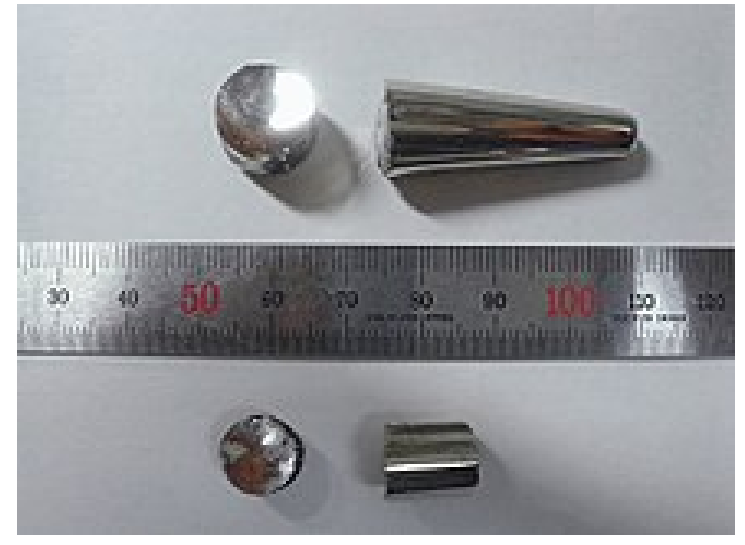

Figure 7. Samples of amorphous metal in millimeter length scale [26].

atomic packing density. Higher packing density leads to lower energy and higher stability [24].

2) Multicomponent system: With higher number of constituent elements (typically more than three elements), the confusion principle prevails indicating that the alloy cannot select viable crystal structures lading to enhanced glass forming ability.

3) Atomic size: The wider the atomic size $(>12 \%)$ the better is the glass forming ability.

4) The combination of constituents should have negative heat of mixing.

5) The composition has a deep eutectic. This was especially true for simple compositions (binary and ternary) as the compositions near to eutectics have lower melting points and stable liquid phase.

The rules indicated above should be taken as guidelines as the laws for quantitative composition design are still unknown and more efforts are required in this area [24]. With the synthesis of BMGs, various characterizations studies revealed the following notable properties exhibited by glassy alloys [23] [24] [25] [26]: 1) extremely high strength ( 1 - $2 \mathrm{GPa})$ at low temperatures, 2$)$ high elastic strain limit $(\sim 1 \%-2 \%), 3)$ high hardness, 4$)$ high flexibility at high temperatures, 5) excellent wear resistance, 6) excellent corrosion resistance due to absence of grains and grain boundaries, and 7) extraordinary formability and superplasticity.

While the experimental investigations have validated the above properties, underlying mechanisms are still not well understood for many of the above properties. The main limitations of metallic glasses include: 1) dimensional limitations, 2) metastable nature, 3) low ductility at low temperatures, and 4) low elastic modulus.

Some of the applications of glassy alloys include: 1) as a soft magnetic material in electronic devices, automobiles and electrical power transmission, 2) as biomedical materials due to their good corrosion resistance in physiological solution [27], 3) in MEMS and NEMS due to their extraordinary formability, 4) in sporting goods due to their high strength and elastic limit, 5) as spring materials 
because of large elastic strain limit, 6) permeation membranes and separator membranes, and 7) optical mirror devices as the metallic surface is more reflective due to absence of grain boundaries.

In recent years, researchers have also utilized metallic glasses as reinforcement in light matrices based on aluminum and magnesium and reported significant improvements in properties [25]. As an example, the use of micron length scale $\mathrm{Ni}_{60} \mathrm{Nb}_{40}$ reinforcement in commercially pure magnesium (Figure 8) led to: 1) an approximately $120 \%$ improvement in microhardness, 2 ) an improvement in compressive strength and ductility, and 3) an improvement in damping.

The improvement was primarily attributed to their metallic nature leading to good interfacial bonding, delayed fracture of reinforcement and fairly uniform distribution in matrix. The results were superior to ceramic particles as ceramic particles tend to exhibit early initiation of particle damage mechanisms resulting in the underutilization of properties enhancement capabilities of reinforcement especially when used in micron and higher length scales.

\section{Composite Metals}

Conventionally alloys are formulated based on phase diagrams and the atoms of constituent elements are mixed during the liquid or solid state processing. The outcome is a thermodynamically stable solid solution phase and precipitates that are further manipulated through heat treatment and secondary processing for realizing the desired application driven end properties. Composite metals, on the contrary, involve the combination of two metals which may be immiscible [28] or miscible [29] with each other. To qualify as composite metal both the metals should be identifiable in their native form following processing with insignificant formation of solid solution or precipitation phases. The choice of element that forms the matrix and the one that form the reinforcement phase can be made based on the target properties that need to be realized. Composite metals can be processed using traditional liquid and solid phase routes. For the miscible metal-metal system, the processing needs to be controlled to avoid reaction between two metals and the techniques such as powder metallurgy method using

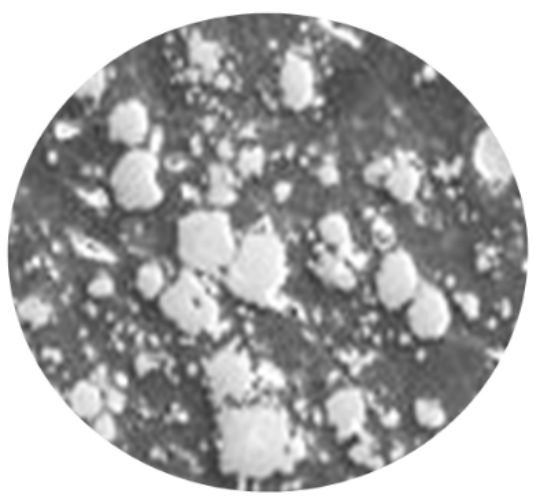

Figure 8. Micrograph of $\mathrm{Mg} / \mathrm{Ni}_{60} \mathrm{Nb}_{40}$ composite. $\mathrm{Ni}_{60} \mathrm{Nb}_{40}$ reinforcement was amorphized using the technique of ball milling. 
microwave sintering can be successfully used. For the immiscible system, conventional casting techniques can be conveniently used for bulk production. The composite metal systems have shown improvement in the following properties over their dominant matrix counterpart [10]: 1) elastic modulus, 2) strength (tensile and compressive), 3) ductility, 4) damping, 5) dimensional stability, and 6) hardness.

The composite metals can be classified as metastable ( $\mathrm{Mg}-\mathrm{Al})$ as the processing is controlled to avoid their interaction and thermodynamically stable such as $\mathrm{Mg}$-Ti and Mg-Mo system where the two metals are immiscible and non-reactive (Figure 9) [28] [29].

To note as shown in Figure 9, the length scale of the reinforcement can be chosen from nano-length scale to millimeter length scale and from continuous to interconnected reinforcement [10] [28] [29]. The main advantages of composite metals include:

1) Deviation from conventional norm of designing alloys and realizing properties that are otherwise not achievable in conventional alloys.

2) Good interfacial bonding between metal servings as matrix with the one serving as reinforcement. The good interfacial bonding leads to superior mechanical properties by delaying the onset of crack nucleation in the presence of stresses.

3) A wide spectrum of properties between metals to design a new series of materials. For example, $\mathrm{E}=40 \sim \mathrm{GPa}$ for $\mathrm{Mg}$ and $\mathrm{E}=\sim 200 \mathrm{GPa}$ for iron allows the variation in elastic modulus that can be realized when combining these two metals.

The properties of some of the composite metals are shown in Table 3.

The advantages associated with designing composite metals give them multiple degrees of freedom to realize properties that are required by end application. Further, the properties of composite metals can be tailored through the judicious utilization of conventional and new secondary processing techniques such as equi-channel angular processing and friction stir processing.

\section{High Entropy Alloys}

High entropy alloys (HEAs) are a new advancement in alloy design that is principally based on entropy of mixing $\left(\Delta \mathrm{S}_{\text {mix }}\right)$ and enthalpy of mixing $\left(\Delta \mathrm{H}_{\text {mix }}\right)$ [30] [31] [32]. HEAs comprise of at least 5 elements each having weight percentage between 5 to $35 \%$. For the likelihood of having a simplified microstructure besides

Table 3. Mechanical properties of selected composite metals.

\begin{tabular}{cccccc}
\hline Materials & $\begin{array}{c}\text { Reinforcement } \\
(\text { Vol.\%) }\end{array}$ & $\begin{array}{c}0.2 \% \text { YS } \\
(\mathrm{MPa})\end{array}$ & $\begin{array}{c}\text { UTS } \\
(\mathrm{MPA})\end{array}$ & Ductility (\%) & $\begin{array}{c}\text { Work of } \\
\text { Fracture }\left(\mathrm{J} / \mathrm{m}^{3}\right)\end{array}$ \\
\hline $\mathrm{Mg}$ & - & $100 \pm 4$ & $258 \pm 16$ & $7.7 \pm 1.2$ & $20.2 \pm 2.6$ \\
$\mathrm{Mg} / 5.6 \mathrm{Ti} \mathrm{P}$ & 2.2 & $163 \pm 12$ & $248 \pm 9$ & $11.1 \pm 1.4$ & $25.7 \pm 2.9$ \\
$\mathrm{Mg} / 9.6 \mathrm{Ti} P$ & 4.0 & $154 \pm 10$ & $239 \pm 5$ & $9.5 \pm 0.3$ & $20.7 \pm 1$ \\
\hline
\end{tabular}




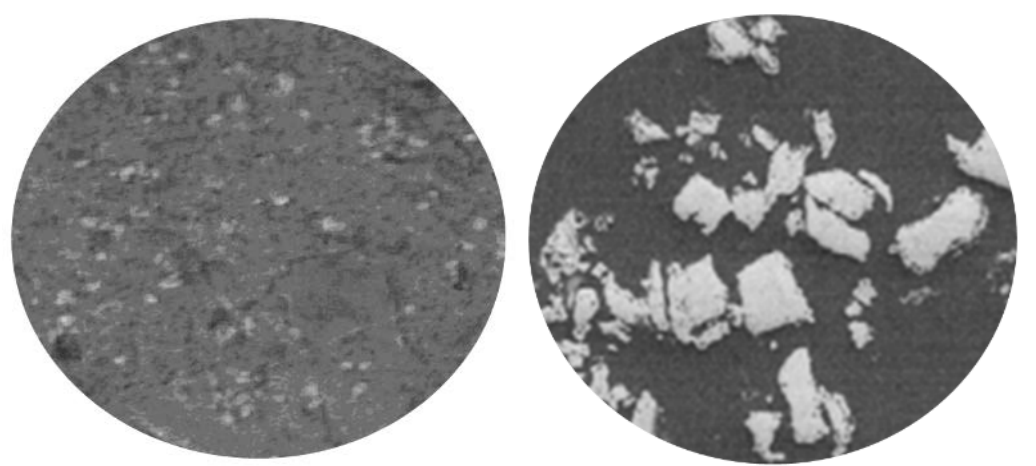

Figure 9. Micrograph of Mg-1.5 wt\% Al (nano-size Al) composite metal (on left) and Mg-9.6 wt\% Ti (micron size Ti) composite metal (on left).

having many elements, HEAS should have entropy of mixing in the range of 11 $\leq \Delta \mathrm{S}_{\text {mix }} \leq 19.5 \mathrm{~J} / \mathrm{K}$ mol and enthalpy of mixing in the range of $-22 \leq \Delta \mathrm{H}_{\text {mix }} \leq 7$ $\mathrm{kJ} / \mathrm{mol}$ [32]. Initially HEAs were developed for high temperature applications with a density hovering around $10 \mathrm{~g} / \mathrm{cc}$ and later efforts were made to develop light weight HEAs [33]. Conventional processing techniques such as powder metallurgy and casting routes can be utilized for synthesizing HEAs indicating that industrial production is not a major issue but the challenge is to find the composition that suits the end application. Table 4 provides HEAs processed using different methods and with different densities and crystal structure [33].

Typical microstructure of a HEA is shown in Figure 10.

For the initially developed HEAs, some of the extraordinary properties displayed included: 1) high hardness (100 to $1100 \mathrm{Hv}$ ), 2) work hardening capacity, 3) wear resistance, 4) high temperature precipitation hardening $\left(600^{\circ} \mathrm{C}\right.$ to $1000^{\circ} \mathrm{C}$ ), and 5) anti-oxidation and anti-corrosion resistance. Selected properties of HEAs exhibiting a wide range of densities are shown in Table 5 and Table 6 [33].

In view of these properties, some of the cited and potential applications include [31] [33]: 1) engine materials for withstanding mechanical properties and corrosion degradation at higher temperatures, 2) nuclear materials with low irradiation damage, 3) marine structures for improved corrosion and erosion resistance, 4) cryogenic applications (liquefied gas storage) e.g. CrMnFeCoNi alloy, 5) in food preservation and cooking ware, 6) to suppress electromagnetic interference, 7) as coatings on tools and machine component due to their high hardness and wear resistance, 8) high temperature applications such as in waste incinerators, 9) transportation sector, 10) biomedical sector, 11) as functional coatings for corrosion and wear resistance, 12) as hydrogen storage materials.

Recently, researchers have also used HEA in the powder form as reinforcement in magnesium matrix [34]. Key beneficial outcomes included: 1) microstructural refinement, 2) an increase in hardness of $\mathrm{Mg}$ by 1.7 times, and 3) an increase in compressive strength up to $79 \%$ without a compromise in ductility.

While HEAs have shown a different path in alloy design and a different spectrum of properties, it rests to be seen whether they can qualify through some of 


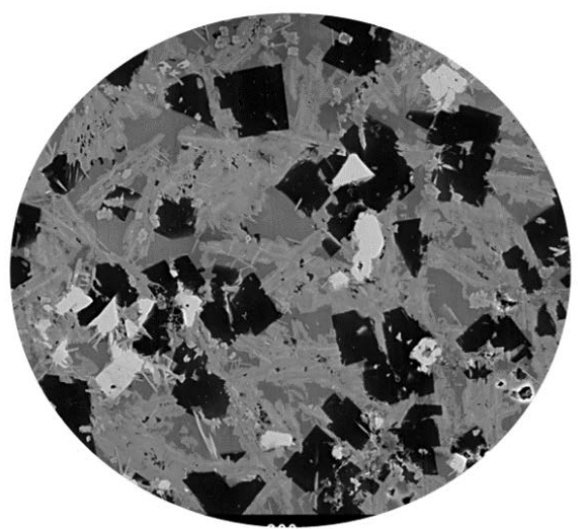

Figure 10. SEM micrograph of Light Weight $\mathrm{Al}_{35} \mathrm{Mg}_{30} \mathrm{Si}_{13} \mathrm{Zn}_{10} \mathrm{Y}_{7} \mathrm{Ca}_{5}$ High Entropy Alloy.

Table 4. Processing routes, density and crystal structure of HEAs [33].

\begin{tabular}{cccc}
\hline Alloy & Density $(\mathrm{g} / \mathrm{cc})$ & Process & Phase \\
\hline NbTiVTa & 11.49 & Arc melting & BCC \\
$\mathrm{Al}_{26.6} \mathrm{Nb}_{23.8} \mathrm{Ti}_{25.1} \mathrm{~V}_{24.5}$ & 5.59 & Casting & BCC \\
$\mathrm{Al}_{20} \mathrm{Be}_{20} \mathrm{Fe}_{10} \mathrm{Si}_{15} \mathrm{Ti}_{35}$ & 3.91 & Casting & 3 phases \\
& & & HCP + Al-Mn \\
$\mathrm{Mg}_{43}(\mathrm{MnAlZnCu})_{57}$ & 2.51 & Induction melting & icosahedral \\
& & Quasi-crystal & FCC \\
$\mathrm{Al}_{20} \mathrm{Li}_{20} \mathrm{Mg}_{10} \mathrm{Sc}_{20} \mathrm{Ti}_{30}$ & 2.67 & &
\end{tabular}

Table 5. Microhardness exhibited by HEAs with wide range of densities.

\begin{tabular}{|c|c|c|c|}
\hline \multirow{2}{*}{ Alloy } & \multirow{2}{*}{ Density (g/cc) } & \multicolumn{2}{|c|}{ Micro-hardness (Hv) } \\
\hline & & As Solidified & homogenised \\
\hline NbTiVTa & 11.49 & \multicolumn{2}{|c|}{ NA } \\
\hline $\mathrm{Al}_{26.6} \mathrm{Nb}_{23.8} \mathrm{Ti}_{25.1} \mathrm{~V}_{24.5}$ & 5.59 & \multicolumn{2}{|c|}{$448 \pm 12$} \\
\hline $\mathrm{Al}_{20} \mathrm{Be}_{20} \mathrm{Fe}_{10} \mathrm{Si}_{15} \mathrm{Ti}_{35}$ & 3.91 & \multicolumn{2}{|c|}{911} \\
\hline $\mathrm{Mg}_{43}(\mathrm{MnAlZnCu})_{57}$ & 2.51 & \multicolumn{2}{|c|}{255} \\
\hline $\mathrm{Al}_{20} \mathrm{Li}_{20} \mathrm{Mg}_{10} \mathrm{Sc}_{20} \mathrm{Ti}_{30}$ & 2.67 & 591.4 (as milled) & 499.6 (annealed at $500^{\circ} \mathrm{C}$ ) \\
\hline
\end{tabular}

Table 6. Compressive response of different HEAs [33].

\begin{tabular}{ccccc}
\hline Alloy & Density $(\mathrm{g} / \mathrm{cc})$ & Yield Stress $(\mathrm{MPa})$ & Peak Stress (MPa) & Fracture Strain $(\%)$ \\
\hline NbTiVTa & 11.49 & 1092 & $\mathrm{NA}$ & $>50$ \\
$\mathrm{Al}_{26.6} \mathrm{Nb}_{23.8} \mathrm{Ti}_{25.1} \mathrm{~V}_{24.5}$ & 5.59 & 1020 & 1318 & 5 \\
$\mathrm{Mg}_{33}(\mathrm{MnAlZnCu})_{67}$ & 3.26 & 437 & 437 & 3.41 \\
$\mathrm{Mg}_{43}(\mathrm{MnAlZnCu})_{57}$ & 2.51 & 500 & 500 & 3.72 \\
$\mathrm{Mg}_{45.6}(\mathrm{MnAlZnCu})_{54.4}$ & 2.30 & 482 & 482 & 4.06 \\
\hline
\end{tabular}

the issues such as: 1) economic feasibility, 2) clear superiority over conventional alloys in terms of mechanical properties, and 3) joining capability. 


\section{Future Directions in Alloy Development}

From the early stages of human civilization till now, metal based alloys are constantly being developed even in the case of most traditional and widely used metal such as iron. The pursuit of alloy development will never end and more superior properties or a combination of properties will always be sought governed by ever changing service requirements in the constantly developing and advancing area of engineering applications. The alloy development work will continue as long as the pursuit of engineers and doctors will continue to bring more comfort to human's life. The rules governing the development of traditional alloys and amorphous alloys are reasonably well established. High entropy alloys are being actively developed over almost 14 years and reasonable success has been made for high density HEAs $(\rho \sim 10 \mathrm{~g} / \mathrm{cc})$. Challenges remain and being addressed to develop light weight HEAs for weight critical applications specially targeted to reduce $\mathrm{CO}_{2}$ emissions. With the extent of activities going on in the area of LWHEAs, it is expected that targeted solutions will be realized in next 5 years. Another window of alloy development that is not yet addressed relates to medium entropy alloys ( $\left.1.5 \mathrm{R} \geq \Delta \mathrm{S}_{\text {conf }} \geq 1 \mathrm{R}\right)$. Medium entropy alloys are again multicomponent alloys that are intermediate between traditional alloys $\left(\Delta \mathrm{S}_{\text {conf }} \leq\right.$ $1 \mathrm{R}$ ) and high entropy alloys ( $\left.\Delta \mathrm{S}_{\text {conf }} \geq 1.5 \mathrm{R}\right)$. A judicious choice of alloying elements based on their capability to constructively interact with each other may lead to development of microstructures capable of demonstrating the properties that may well complement other metal based alloys conventionally used and developed currently. In essence, there are still gaps in alloy development which need to be filled through intelligent use of core fundamentals of materials science and engineering.

\section{Acknowledgements}

The authors would like to acknowledge the Ministry of Education Academic Research Funding (WBS\# R-265-000-586-114) for the financial support.

\section{Conflicts of Interest}

The author declares no conflicts of interest regarding the publication of this paper.

\section{References}

[1] Van Vlack, L.H. (1989) Elements of Materials Science and Engineering. 6th Edition, Addison Wesley Publishing Company, Boston.

[2] Smith, W.F. (1996) Principles of Materials Science and Engineering. 3rd Edition, McGraw-Hill Inc., New York.

[3] Gupta, M. and Meenashisundaram, G.K. (2015) Insight into Designing Biocompatible Magnesium Alloys and Composites. Springer, Berlin.

[4] Cahn, J.W. (1983) A Historical Perspective on the Utilization of Phase Diagrams for Precipitation Hardening. Bulletin of Alloy Phase Diagrams, 4, 349-350. https://doi.org/10.1007/BF02868070 
[5] https://en.wikipedia.org/wiki/Iron_pillar_of_Delhi

[6] Tamarin, A.D., Kal'tman I.I. and Vasil'ev, L.A. (1968) Vibrofluidized Bed for Quenching. Translated from Metallovendenie i Termicheskaya Obrabotka Metallov, No. 5, 11-19.

[7] Veazey, M.V. (2005) Chemistry International, 27. http://iupac.org/publications/ci/2005/2706/3_veazey.html

[8] Hatch, J.E. (1984) Aluminum Properties and Physical Metallurgy. Chapter 5, ASM International, 1, 134-199.

[9] https://en.wikipedia.org/wiki/Katana

[10] Gupta, M. and Nai, S. (2011) Magnesium, Magnesium Alloys and Magnesium Composites. John Wiley \& Sons, Hoboken.

[11] By CSIRO, CC BY 3.0.

https://commons.wikimedia.org/w/index.php?curid=35482531

[12] For Ni Based Alloy. https://www.azom.com/article.aspx?ArticleID=7804

[13] For Brass. https://www.azom.com/article.aspx?ArticleID=6341

[14] 304 Steel. http://asm.matweb.com/search/SpecificMaterial.asp?bassnum=mq304a

[15] Maraging Steel. http://www.matweb.com/search/DataSheet.aspx?MatGUID=de22e04486ff4598a260 $27 \mathrm{abc} 48 \mathrm{e} 6382 \& \mathrm{ckck}=1$

[16] (2004) EN10025:2004 European Hot-Rolled Structural Steel Standard.

[17] https://en.wikipedia.org/wiki/Ti-6Al-4V

[18] https://en.wikipedia.org/wiki/7075_aluminium_alloy

[19] Tekumalla, S., Nandigam, Y., Bibhanshu, N., Rajashekara, S., Yang, C., Suwas, S. and Gupta, M. (2018) A Strong and Deformable In-Situ Magnesium Nanocomposite Igniting above $1000{ }^{\circ} \mathrm{C}$. Scientific Reports, 8, 7038. https://doi.org/10.1038/s41598-018-25527-0

[20] https://www.dynacast.com/az91d

[21] https://www.azom.com/article.aspx?ArticleID=6707

[22] ASM Handbook Committee (1990) ASM Handbook, Vol. 2: Properties and Selection: Nonferrous Alloys and Special-Purpose Materials. ASM Handbook Committee, $62-122$.

[23] Klement, W., Willens, R.H. and Duwez, P. (1960) Non-Crystalline Structure in Solidified Gold-Silicon Alloys. Nature, 187, 869-870. https://doi.org/10.1038/187869b0

[24] Chen, M. (2011) A Brief Overview of Bulk Metallic Glasses. NPG Asia Materials, 3, 82-90. https://doi.org/10.1038/asiamat.2011.30

[25] Jayalakshmi, S. and Gupta, M. (2015) Metallic Amorphous Alloy Reinforcements in Light Metal Matrices. https://doi.org/10.1007/978-3-319-15016-1

[26] https://en.wikipedia.org/wiki/Amorphous_metal

[27] Morrison, M.L., et al. (2005) The Electrochemical Evaluation of a Zr-Based Bulk Metallic Glass in a Phosphate-Buffered Saline Electrolyte. Journal of Biomedical Materials Research Part A, 74A, 430-438. https://doi.org/10.1002/jbm.a.30361

[28] Hassan, S.F. and Gupta, M. (2002) Development of Ductile Magnesium Composite Materials Using Titanium as Reinforcement. Journal of Alloys and Compounds, 345, 246-251. https://doi.org/10.1016/S0925-8388(02)00413-9

[29] Zhong, X.L., Wong, W.L.E. and Gupta, M. (2007) Enhancing Strength and Ductility 
of Magnesium by Integrating It with Aluminum Nanoparticles. Acta Materialia, 55, 6338-6344. https://doi.org/10.1016/j.actamat.2007.07.039

[30] Cantor, B., Chang, I., Knight, P. and Vincent, A. (2004) Microstructural Development in Equiatomic Multicomponent Alloys. Materials Science and Engineering: $A$, 375, 213-218. https://doi.org/10.1016/j.msea.2003.10.257

[31] Murty, B.S., Yeh, J.W. and Ranganathan, S. (2014) High-Entropy Alloys. Elsevier Science.

[32] Guo, S. and Liu, C.T. (2011) Phase Stability in High Entropy Alloys: Formation of Solid-Solution Phase or Amorphous Phase. Progress in Natural Science: Materials International, 21, 433-446. https://doi.org/10.1016/S1002-0071(12)60080-X

[33] Kumar, A. and Gupta, M. (2016) An Insight into Evolution of Light Weight High Entropy Alloys: A Review. Metals, 6, 199. https://doi.org/10.3390/met6090199

[34] Tun, K.S., Zhang, Y., Parande, G., Manakari, V. and Gupta, M. (2018) Enhancing Hardness and Compressive Response of Magnesium Using Complex Composition Alloy Reinforcement. Metals-Open Access Metallurgy Journal, 8, 276.

https://doi.org/10.3390/met8040276 